LIBRO

Renato Cristi y Pablo Ruiz-Tagle: La República en Chile. Teoría y Práctica del Constitucionalismo Republicano (Santiago: LOM, 2006).

\title{
RENATO CRISTI Y PABLO RUIZ-TAGLE: LA REPÚBLICA EN CHILE. TEORÍA Y PRÁCTICA DEL CONSTITUCIONALISMO REPUBLICANO
}

\author{
Alfredo Jocelyn-Holt Letelier
}

$\mathrm{L}$ literatura constitucional en Chile no es extensa; tampoco es objeto de revisión y crítica periódica. En general, nos remite al articulado específico de las distintas cartas constitucionales mediante glosas o comentarios puntuales, como en las obras de tipo manual o técnico constitucional, creando la impresión, obviamente falsa, de que la historia constitucional sería una historia de estancos disconexos. En cambio, cuando el análisis se vuelve algo más ambicioso, abordándose por ejemplo el clima y el entorno de las “ideas políticas” que estarían operando en determinados momentos, llama la atención que los estudios se empantanen en las luchas partidistas contingentes y no reparen, sin embargo, en la posibilidad de que esté también en juego una continuidad histórica de más larga duración. Si a ello le agregamos que nuestra reflexión constitucional no suele ahondar en un contexto filosófico y legal más amplio que el estrictamente local, podemos concluir, sin riesgos de exageración, que estamos ante una disciplina, para ponerlo en términos benévolos, un tanto decaída.

Valga el anterior diagnóstico para resaltar cuán valioso y original es el libro de Cristi y Ruiz-Tagle. Texto que más allá de sus aportes sugerentes y debatibles, según la lectura a que sin duda llama, cuando no se propone provocar a sabiendas, es riquísimo en alcances normativos, teóricos, doctri-

Alfredo Jocelyn-Holt Letelier. Historiador; D. Phil., Oxford. Profesor de la Universidad de Chile. 
narios, históricos, relativos al derecho en sus distintas ramificaciones y práctica, y por último, en cuanto a proposiciones específicas respecto al ordenamiento actual, objeto de renovada inquietud ahora último. Si hemos de aceptar una, a lo menos, de las conclusiones de este estudio, por tanto, concordemos con sus autores, que nuestra institucionalidad no nació recién ayer; que, por el contrario, a casi doscientos años de que hablamos de republicanismo sin parar en nuestro país, bien vale la pena, sentarnos a revisar y repensar su trayectoria y validez tanto pasada como presente. No vaya a ser que, de lo contrario, se siga abusando del término como mero eslogan político publicitario.

El libro se inicia con una exposición general acerca de la "Teoría del Constitucionalismo Republicano”, donde tanto Cristi como Ruiz-Tagle abordan la pregunta central: en qué consistiría el constitucionalismo, deteniéndose en precisiones y discusiones relativas a la naturaleza de la democracia en el mundo moderno, sus fundamentos, el por qué surgen las constituciones positivas y cómo la doctrina define la idea de Poder Constituyente. En oposición a la tradición propiamente republicana que arranca las constituciones de un tronco ilustrado anti-absolutista y revolucionario, que por lo mismo valora aciertos como la separación de poderes y la revisión judicial, Cristi ofrece una tipificación de una tradición en paralelo, crítica de la anterior, de corte, por lo mismo, autoritaria, remitiéndose para dichos efectos a las obras de G. W. F. Hegel y Carl Schmitt.

En la segunda parte del libro, ciertamente la más llamativa, nuestros dos autores ahondan en cómo el republicanismo ha ido evolucionando en Chile hasta convertirse en "la gran idea a partir de la cual se ha desarrollado nuestra vida política independiente” (p. 11). Nuevamente, aquí, vemos que el libro se bifurca en dos grandes líneas. Por un lado, Ruiz-Tagle profundiza en la historia política del país, desde la Independencia a nuestros días, periodificando estos ya casi doscientos años, en cinco etapas o "repúblicas”: la República Independiente (1810-1833), la República Autoritaria (1833-1871), la República Liberal (1871-1924), la República Democrática (1932-1973), y la República Neoliberal (1990 en adelante). A su vez, en consecutivos capítulos posteriores, Cristi y Ruiz-Tagle se detienen en la influencia, a su juicio, perniciosa ejercida por Carl Schmitt en Chile, su recepción en el pensamiento constitucional de Jaime Guzmán, y cómo ésta se plasma en la Constitución de 1980, texto "gatopardiano" según RuizTagle, que a pesar de sus numerosas enmiendas y reformas posteriores ha mantenido un sesgo autoritario presidencialista hasta nuestros días.

En la tercera y cuarta parte de este largo y complejo libro (431 páginas), la discusión, de nuevo, nos remite a un análisis teórico para luego 
proceder a aterrizar en su práctica concreta en Chile, esta vez referido a los derechos fundamentales y cómo su definición y preservación sirven para afianzar la democracia.

Explica esta discusión siempre en paralelo con que se construye el libro, la tesis claramente enunciada por los autores: “A pesar de la fuerza original del republicanismo cívico en la historia de Chile, en los últimos decenios se ha desarrollado una teoría y una práctica constitucional alejada de este ideal. Intentamos aquí una exposición y crítica de esta forma de constitucionalismo autoritario, anti-republicano, a la vez anti-democrático y anti-liberal, que se impone en Chile durante el régimen militar de Pinochet. A partir de 1989, se ha avanzado en la recuperación del lenguaje político que marca nuestra senda republicana original. La idea es consolidar ese avance estableciendo las instituciones que permitan su desarrollo. En particular, nos interesa definir las tareas de un constitucionalismo republicano (libertad como ausencia de dominación, imperio de la ley, separación de poderes públicos, apertura de canales de participación ciudadana y protección de grupos minoritarios) comprometido con valores democráticos (autogobierno, igualdad de oportunidades, intervención del Estado a favor de la justicia, deliberación y decisión públicas, educación pública gratuita y obligatoria)" (p. 12).

Como bien se puede apreciar de esta breve síntesis, estamos ante un libro que se propone provocar, no haciéndole el asco a la discusión y a la crítica. En efecto, la proposición que sirve para armar todo este entramado teórico-práctico — que existiría una tradición constitucional, liberal republicana, y no sólo textos constitucionales normativos específicos- es particularmente sugerente. Dicho de otro modo, el que se nos muestre que el derecho es bastante más que "dogmática jurídica”, que es, también, política e ideología, filosofía y pensamiento, cuando no llamados a actuar sobre la realidad dada, en fin, que se nos haga tomar conciencia de que es así como se ha gobernado y desgobernado con ayuda del derecho a este país por ya casi doscientos años, le estaría devolviendo una dimensión clave al derecho que el academicismo profesional tiende a olvidar si es que no despreciar.

En un plano, más específico, resulta especialmente provocadora la insistencia en que el republicanismo liberal es una tradición sólida, pero a la vez continuamente amenazada, por un autoritarismo constitucional que periódicamente aflora entre nosotros y se nutre de corrientes ideológicas potentes. Igualmente estimulantes son, también, ciertos aportes y alcances de índole historiográficos. Por de pronto, la periodificación en cinco "repúblicas” que pone de relieve un sorprendente paralelismo de perfil francófilo 
por parte de nuestra historia política institucional; su insistencia en que el republicanismo es un proceso acumulativo en que se conjugan cartas constitucionales, prácticas, reformas, interpretaciones, y debate doctrinario; la valoración del período formativo inicial, en especial de la Constitución de 1828 que para Ruiz-Tagle sería el texto constitucional fundante y no la Carta de 1833; el rescate de las tesis de Julio Heise que remontan el parlamentarismo a la década de 1860 desechando, pues, la visión peregrina que hace arrancar a este régimen exclusivamente desde 1891; el acertado alcance de que en contra del parlamentarismo estaría operando una "leyenda negra" que debemos a Alberto Edwards y otros, sin asidero alguno salvo el querer apuntalar un presidencialismo autoritario sobre la base de una descalificación mitificante antiparlamentaria y — si se me permite un agregado personal- antioligárquica. También me parece incisivo el que se subraye el carácter de "dictadura legal” de la Constitución de 1925, siguiendo en esto a Kelsen $^{1}$, y el que se abogue a favor de un escepticismo cauto y sano en cuanto a que el desarrollo supuestamente "democrático" de Chile habría sido relativo, esto último acogiendo una tesis de Sofía Correa al respecto en la que se enfatizan logros institucionales y partidistas por sobre los estrictamente participativos antes de que se expandiera el sufragio y surgieran los movimientos de masas de las décadas de $1960 \mathrm{y}$ tempranos $70^{2}$.

Menciono estos aciertos porque ilustran la fuerte carga revisionista del libro. En el fondo, Ruiz-Tagle y Cristi tienen toda la razón: si queremos desembarazarnos del supuesto autoritarismo constitucional que opera en paralelo y a contracorriente de la tradición republicana liberal, debemos hacer una profunda revisión crítica de una serie de lugares comunes políticamente correctos que enturbian el diagnóstico histórico político.

De igual manera, Cristi y Ruiz-Tagle son particularmente combativos cuando desenmascaran con rigor la tradición schmittiana, antes hegeliana, con que se ha pretendido subvertir los propósitos constitucionales antiautoritarios que surgen a partir de la Revolución francesa. Otro tanto cabría decirse de la genealogía posterior que el libro puntualiza de esta tradición antiliberal y antidemocrática en Chile, la cual habría desembocado en la recepción del pensamiento de Schmitt entre nosotros, su vinculación con el neoliberalismo hayekiano vía ciertas apostasías y volteretas doctrinarias en que habría incurrido Jaime Guzmán —argumento que Cristi ya postulara en

${ }^{1}$ Cristi y Ruiz-Tagle (2006), pp. 121-122, tomado de Hans Kelsen, “Observaciones sobre la Constitución Chilena”, en Anuario de Filosofía Jurídica y Social, vol. 21 (2003), pp. 643-647.

${ }^{2}$ Cf. Correa, Sofía: "La Democracia que Tuvimos, la Democracia que No Fue" (2000). 
su valioso libro anterior sobre la influencia que ejerciera en la Constitución de $1980^{3}$ - , la acogida que tendría esta contra-tradición autoritaria entre juristas de nuestras dos principales casas de estudios, en especial de la Universidad Católica, y, por último, los atrincheramientos ultra celosos encaminados a no querer someter al neoliberalismo a una seria discusión y eso que existirían imputaciones severas de que éste nos habría llevado a un mercantilismo brutal y atomizante, debilitador de ciertos rasgos comunitarios aportados por la tradición republicana.

¿Duro el libro de Cristi y Ruiz-Tagle? Claro que sí. Pero más que duro, yo diría que desafiante. En efecto, por muy de acuerdo que uno esté con la inspiración y la línea general aquí argumentada, pienso que se les podría rebatir con igual grado de exigencia que el que emplean, y, enhorabuena. Puesto que nadie tiene la última palabra en este tipo de materias, a la conversación no cabe ponerle punto final. Permítaseme, pues, abusar del tenor controversial de este libro, y plantear algunas reservas puntuales que me suscita su lectura.

Cristi y Ruiz-Tagle sostienen que nuestra gran tradición constitucional es republicana y liberal. Hasta ahí ningún problema. El asunto se complica un tanto, sin embargo, cuando comenzamos a examinar la letra chica con que se definen estos dos términos. Los autores afirman en página 19 que "resulta incongruente un republicanismo cívico que no sea democrático". ¿Será tan así? De hecho, argumentan, en un apartado más conciliador, que el liberalismo sería un "ecumenismo de muchas sectas”. Son bien sabidos, además, los numerosos ejemplos históricos de repúblicas que nunca fueron democráticas: lo que nuestros autores asocian y llaman a veces tradición "neo-romana", las repúblicas de algunas ciudades-estados italianas, la república veneciana, y por cierto, el republicanismo oligárquico chileno, inicialmente censitario luego restringido hasta bien adentrado el siglo $\mathrm{XX}^{4}$.

Un reparo similar se les podría hacer a los autores respecto a los alcances que los lleva a denostar cierta tradición militarista o dictatorial caudillesca en América Latina y Chile en particular, en tanto supuestas "regresiones" del modelo republicano. El problema es histórico y no fácil de dilucidar. ¿Las dictaduras latinoamericanas son "aberraciones” o son fenómenos explicables a partir de adhesiones políticas legítimas como el republi-

\footnotetext{
${ }^{3}$ Cristi, Renato: El Pensamiento Político de Jaime Guzmán: Autoridad y Libertad (Santiago: LOM, 2000).

${ }^{4}$ Véase, por ejemplo, la relación entre humanismo cívico y republicanismo en la Italia del siglo XV, en la obra magistral, originalmente publicada en 1955, de Baron, Hans: The Crisis of the Early Italian Renaissance: Civic Humanism and Republican Liberty in the Age of Classicism and Tyranny (1966).
} 
canismo liberal? En opinión de muchos, no hay nada más republicano, si bien no necesariamente liberal aunque a veces lo son, que las dictaduras latinoamericanas; sin ir más lejos, pensemos en Bolívar. Éstas prosperan precisamente porque, desde muy temprano, queda vedada la posibilidad de restaurar las monarquías y el republicanismo era el único otro modelo, por aquel entonces, disponible. Es más, cabe recordar que los modelos bonapartistas surgen del seno mismo de la experiencia francesa, tanto en su versión republicana como revolucionaria. Nada de raro tiene, por tanto, que aquí en América se recepcionen estos “otros” modelos derivados del republicanismo; no es que haya sido necesario tener que revertir al absolutismo español pre-independentista. No hubo, hacia los años 30 del siglo XIX, tal "reacción colonial" de que habla la historiografía tradicional y que nuestros autores lamentablemente recogen (p. 14); de igual modo, no hubo tampoco un autoritarismo conservador que podamos denominar "portaliano"5. Ésta fue siempre una sociedad autoritaria, por lo mismo que patricia y señorial; la posibilidad de una democratización revolucionaria fue siempre percibida por la elite dirigente tradicional como una amenaza al orden establecido. Ergo, tanto Liberales como Conservadores fueron autoritarios (Santa María o Balmaceda tanto como Prieto o Bulnes), y ambos, Liberales y Conservadores (así con letra mayúscula para adscribirlos a los "partidos” o tiendas políticas con que se asociaban) fueron igualmente liberales y republicanos en un sentido general. De haber sido algo concreto, uno podría sostener que el liberalismo republicano entre nosotros fue, por tanto, una propuesta antidemocrática y anti-revolucionaria, inicialmente de corte bonapartista, luego "detocquevilleana".

Visto así el asunto, el republicanismo liberal sería mucho más ambiguo y menos puro de lo que quieren conceder Cristi y Ruiz-Tagle en su libro. Históricamente hablando, el republicanismo liberal y sus constituciones responderían, además, a opciones estratégicas políticas de naturaleza más pragmática que a convicciones doctrinarias ortodoxas que es de donde suelen querer hablar nuestros dos autores. Es más, se nublan un tanto cuando asumen un tono histórico retrospectivo correccional. La experiencia histórica no suele comportarse como las normas jurídicas y constitucionales o los modelos filosóficos políticos dictan. Por eso, pienso, que más crucial que las normas a lo que hay que seguir atendiendo es a los sujetos y, en este caso al sujeto elitario, a su comportamiento político flexible y pragmático, entre cuyas muchas estrategias posibles figuran prominente pero no

${ }^{5}$ Sobre el carácter liberal, antes bien que conservador de Portales, y para una refutación del llamado “régimen portaliano", véase mi libro El Peso de la Noche: Nuestra Frágil Fortaleza Histórica (1997). 
excluyentemente las leyes y constituciones. Por cierto, concluir que el republicanismo no es tan sólo una convicción sino una estrategia basada en la cooptación para precisamente neutralizar sus, también, indiscutibles rasgos revolucionarios atenúa considerablemente la línea argumentativa de este libro.

El punto crítico invocado puede parecer insignificante si lo limitamos al siglo XIX, con todo, si nos movemos al siglo XX, dicho reparo se vuelve quizá más evidente. Cristi y Ruiz-Tagle afirman, a lo largo de su libro, que lo que en última instancia define la adhesión a un régimen republicano-liberal es una apuesta incondicional a favor de la igualdad en sentido auténticamente democrático. Si así definimos al republicanismo liberal — conformela cuarta y quinta "repúblicas", las asociadas a la Constitución de 1925 y a la Constitución de 1980 post 1990 serían la culminación y perfección última del proceso que delinean, más aún, si el Poder Constituyente en ambos casos reside, al fin, en el pueblo soberano que es la razón por la cual nuestros dos autores aplauden estos dos "momentos" constitucionales en especial. La experiencia anterior, la decimonónica, sin embargo, si hemos de llevar el argumento antedicho hasta sus últimas consecuencias lógicas, concordemos, sería a lo sumo una suerte de "prehistoria" del republicanismo liberal por lo mismo que las elites políticas y sociales chilenas, de hecho, nunca fueron igualitaristas, ni pro soberanía-popular, ni democráticas. Fueron férreas defensoras del principio de la representación, del control del sufragio (inicialmente a través del Ejecutivo, luego desde los partidos parlamentarios) y de la mantención de un orden social, rural tradicional, jerárquico y estamental. De ser así la evidencia histórica, los planteamientos de Cristi y Ruiz-Tagle exigirían más cautela.

La insistencia, pues, en esta suerte de "Whig interpretation of history" - lineal y progresista, ratificadora si es que no glorificadora de un cierto ascenso presente ${ }^{6}$ - con que se nos quiere convencer en este libro queda de manifiesto cuando nuestros autores pasan por alto el rasgo que probablemente mejor une a las dos propuestas constitucionales del siglo XX, concretamente la alianza cívico-militar entre presidencialismo autoritario y Fuerzas Armadas deliberantes. Alianza que está operando en 1924-1925 con Alessandri-Ibáñez-Grove y el general Mariano Navarrete mediantes; reiterada en 1932 con la vuelta del segundo Alessandri; con el comandante en jefe de la época afirmando a Aguirre Cerda el 38; repetidas veces bajo los gobiernos radicales integrando a oficiales en ejercicio activo al gobierno y entregándole el resguardo de los comicios electorales; con González Videla

${ }^{6}$ Para un análisis y refutación de esta manera de ver la historia, consúltese Butterfield, Herbert: The Whig Interpretation of History (1965). 
y la Ley de Defensa Permanente de la Democracia en clave Guerra Fría; de nuevo con Ibáñez el 52; otra vez más con Prats y Pinochet el 72 y 73, para luego rematar y explicitarse esta trayectoria fáctica en el texto de 1980 (la norma de los "garantes"); confirmada, a su vez, con la permanencia en la comandancia en jefe por parte de Pinochet; la subsistencia pétrea de todo el armazón corporativo y funcionalista (Consejo de Seguridad, senadores designados, etc.) por más de diez años bajo los gobiernos concertacionistas, e incluso bajo el texto refundido de Lagos que sigue consignando, como bien señala Ruiz-Tagle, la doctrina de seguridad nacional. Agreguemos a esto, el excesivo presidencialismo (pensemos en los decretos con fuerza de ley y la potestad reglamentaria), el binominalismo consensualista todavía vigente, y para qué decir una Presidenta perteneciente a la "familia militar", luego reconocida y aplaudida como tal. Todo ello, sin perjuicio, de que el Poder Constituyente haya estado o no en manos del pueblo soberano que es el rasgo que a nuestros dos autores les parece decisivo, capaz de "legitimar" a estas dos experiencias republicanas recientes post 1990.

Pudiera creérseles, pero se hace difícil darles enteramente la razón. La oferta soberana-popular tan atrayente a que se nos quiere invitar, la de un Poder Constituyente de nuevo en manos del pueblo soberano, puede que apele a un sentir republicano revolucionario siempre latente, pero eso no quiere decir que tengamos que denominarlo republicano excluyentemente de otras variaciones, no menos tales, aunque más cautelosas y escépticas respecto a la regla de la mayoría, en última instancia, para muchos (me incluyo), la norma definitoria de la democracia. En otras palabras, intuyo que Cristi y Ruiz-Tagle son más democráticos que liberales, que su libro está escrito por sobre todo desde la convicción, que como todo anhelo ideal, sabemos, es algo voluntarioso, y por eso es que nuestros autores tienden a privilegiar una definición más de tipo democrática comunitarista y estatocrática del republicanismo liberal que republicana y liberal en estricto rigor histórico en lo que nos toca aquí en Chile.

A propósito del sesgo favorable al Estado que se desprende de este libro, fundado en la premisa de que un Estado activo y vigilante puede asegurar un mayor grado de justicia, participación, mejores decisiones y renovación de cuadros a través de una educación pública nacional, ¿̇por qué no pensar, en cambio, que lo que buenamente tuvimos a lo largo del siglo XIX y gran parte del XX, fue más bien un espacio público institucionalizado? Sostener que nuestros logros (más o menos los mismos que señalan Cristi y Ruiz-Tagle, ese no es el punto en discusión) se debieron a un espacio público y no a un Estado, pone el asunto definitivamente bajo otra luz. Desde luego, rescata para el republicanismo una tradición anterior a la 
aparición del Estado, luego escéptica de éste, de su peso y centralidad autoritaria, en suma, de su constructivismo ingenieril y afanes monopólicos. El republicanismo, no lo olvidemos, es una respuesta frontal a la concentración de poderes y decisiones en las monarquías absolutas, creadoras del Estado moderno. Por eso el liberalismo post revolucionario (pensemos en la Francia decimonónica) asume para sí el republicanismo, condiciona los rasgos monárquicos posteriores cuando no los elimina del todo, impide cualquiera restauración del Antiguo Régimen, y hace del parlamentarismo (donde todavía se pueden encontrar los tradicionalistas nostálgicos como, también, después lo estarán los estatistas totalitarios) el centro y tribuna de una política más plural. Sospecho que Cristi y Ruiz-Tagle conciben, en cambio, el liberalismo y por ende el republicanismo como los "liberals" y demócratas norteamericanos del siglo XX. Ahora bien, tengo ciertas dudas que una perspectiva retrospectiva rooseveltiana, o incluso jeffersoniana, sea la más conveniente para entender la carga histórica chilena, más afín a cierta tradición continental europea algo distinta.

Concuerdo, en todo caso con nuestros autores, el republicanismo liberal está aún pendiente. ¿Cómo no estar de acuerdo? En el viejo Chile, oligárquico y señorial, a la vez que auténticamente republicano liberal como nunca antes o después, existía una vocación cívica y pública verdaderamente profunda. He ahí instituciones meritocráticas como las que tuvimos bajo el alero de una educación pública y nacional que permitió en parte que surgiera una clase media profesional, la inclusión bastante temprana de partidos de izquierda en el seno parlamentario, y la respuesta favorable que tuvo la masa popular, una y otra vez, a la hora de movilizársele tras propósitos nacionales (las guerras externas). Todo ello a pesar de que el sistema se erigiera, en no poca medida, sobre la base del acarreo de votos, y la sociedad fuese discriminatoria e injusta, según nuestros estándares tan "exigentes” de un tiempo a esta parte. Estándares que, en ningún caso, parecieran todavía plasmarse en cuanto a distribución de ingreso, acceso a la justicia o una ciudadanía pluralmente representada, por sólo mencionar algunas pocas variables que dejan en evidencia que no somos tanto mejores que ayer. Ahora bien, ¿'se puede tener un republicanismo auténtico con los parlamentarios que actualmente disponemos? ¿No será que cuando los tuvimos, aunque no fuésemos tan democráticos como hoy, gozamos de instituciones más representativas de un sentir público y nacional compartido por todas las fuerzas políticas organizadas? En definitiva, no está tan claro que la "Whig interpretation of history", esa falacia retrospectiva y auto-congratulatoria, funcione del todo bien en nuestro caso particular. 
Cristi y Ruiz-Tagle abogan a favor de un republicanismo que lúcidamente tipifican e ilustran recurriendo a la historia del país y el entorno cambiante de las ideas. Un republicanismo que, sirviendo de columna vertebral constitucional, ha ofrecido en el pasado toda suerte de valores políticos, tales como espíritu público, equilibrio de poderes, defensa de derechos individuales, rechazo de autoritarismos atávicos o más actuales, y sentido nacional en tanto un todo sustentado en lo colectivo y no en meras defensas de intereses privados. Rescatar este trasfondo de casi ya dos siglos es obviamente un recordatorio pertinente y valioso. Ahora bien, calificar a esta tradición republicana de específicamente liberal, que lo es, a la par que pretender revivirla en nuestros días mediante una mayor injerencia del Estado a favor de cierto igualitarismo correctivo que permita recrearnos como una comunidad toda es un salto, sin embargo, que habría que profundizar aún más. Desde luego, obliga a explicar por qué nuestro republicanismo histórico ha sido tan poco democrático en sentido igualitarista no obstante su capacidad para crear instituciones sólidas y plurales. Obliga, también, a desvirtuar el prejuicio, de un tiempo a esta parte, válidamente crítico frente a un Estado intervencionista, tutelar, cuando no arbitrario o totalitario conforme a varios tintes ideológicos, del que hay evidencia de sobra en la historia más reciente de este país. En otras palabras, se nos tiene que convencer que el Estado, sus adeptos y administradores últimos, pueden llegar a ser agentes pro-activos de la libertad y no de otros propósitos más mezquinos como lo son los abanderamientos doctrinarios o simplemente el querer el poder por el mero poder. Este libro, evidentemente, ha sido escrito con objetivos críticos y nobles, cree en una suerte de ascenso histórico; así y todo, no despeja la duda de si la historia pasada, tanto en lo positivo como lo negativo, es tan fácilmente superable.

Me permito un penúltimo alcance a este libro: la portada. Fíjense lo curiosa y ambigua que es la fotografía que sirve de cubierta. La sala de sesiones del Senado del viejo Congreso, en calle Compañía, está vacía. Obviamente, el poder está en otra parte. Así y todo, la sala irradia y mantiene ese porte imponente, histórico, que ningún “arquitecto” últimamente ha sabido repetir o por lo cual haya recibido una comisión restauradora. Vacía de representantes políticos capaces de mantener el "sentido”, que aunque no está visible, sigue latente, se sigue sintiendo. ¡Presente! Por supuesto que sí, aunque, ¿dónde está el poder? O no será mejor decir, ¿dónde está el no-poder, el propósito fiscalizador y sospechoso de todo abuso y arbitrio? Si de eso trata el republicanismo-liberal a la hora de las definiciones.

Por último, traigamos a la discusión otra ilustración igualmente elocuente. En efecto, Simon Schama, comentando el dibujo preparatorio, de 
Jacques Louis David, para una pintura que nunca se terminó y que pretendía retratar ese momento en que todos los asistentes en la cancha techada de tenis del palacio de Versailles juraban fidelidad a la república y condenaban para siempre al absolutismo, cifra su atención en la parte superior del cuadro, una muralla limpia, sin adornos, sin figuras, también, vacía, pero a la que se le insufla un ventarrón de aire y luz desde una ventana abierta al costado ${ }^{7}$. Tiene razón Schama, pues, al poner la atención en ese vacío pendiente. Sabemos demasiado bien lo que pasó después del abrazo fraternal de los protagonistas ilustrados en la parte inferior del dibujo: unos y otros se guillotinaron ${ }^{8}$. La historia del republicanismo es efectivamente doble y ambigua. Cubre tanto el "arriba” como el "abajo” de ese dibujo preparatorio; lo que en su nombre se ha hecho y no se ha hecho todavía.

Pienso que el libro de Cristi y Ruiz-Tagle, fuera de ser un gran estímulo para seguir pensando, debatiendo y discrepando sobre la historia política y constitucional de Chile, posee el enorme mérito de querer apuntar a ese espacio en blanco, aún por llenar, o lo que es lo mismo, quizá, hacer revivir el espíritu que todavía ronda pero no se reedita en la sala vacía del antiguo Congreso nacional.

\section{REFERENCIAS}

Baron, Hans: The Crisis of the Early Italian Renaissance: Civic Humanism and Republican Liberty in the Age of Classicism and Tyranny. Princeton, New Jersey: Princeton University Press, 1966.

Butterfield, Herbert: The Whig Interpretation of History. New York and London: W. W. Norton \& Company, 1965.

Correa, Sofía: “La Democracia que Tuvimos, la Democracia que No Fue”. En Revista de Sociología, No 14, Santiago, Universidad de Chile, 2000.

Cristi, Renato: El Pensamiento Político de Jaime Guzmán: Autoridad y Libertad. Santiago: LOM, 2000.

Darnton, Robert: The Kiss of Lamourette: Reflections in Cultural History. New York and London: W. W. Norton \& Company, 1990.

Jocelyn-Holt, Alfredo: El Peso de la Noche: Nuestra Frágil Fortaleza Histórica. Buenos Aires: Planeta-Ariel, 1997.

Schama, Simon: The Power of Art. New York: BBC Books, 2006.

${ }^{7}$ Véase Schama, Simon: The Power of Art (2006), pp. 210-211.

${ }^{8}$ La misma paradoja es tratada en Darnton, Robert: The Kiss of Lamourette: Reflections in Cultural History (1990), pp. 3-20. 